\title{
DOS ESTUDOS DE USUÁRIOS DA INFORMAÇÃO AOS ESTUDOS EM PRÁTICAS INFORMACIONAIS E CULTURA: uma trajetória de pesquisa
}

\author{
FROM INFORMATION USER STUDIES TO INFORMATION PRACTICES AND CULTURE \\ STUDIES: a research trajectory
}

Carlos Alberto Ávila Araújo ${ }^{1}$

\begin{abstract}
${ }^{1}$ Doutor em Ciência da Informação pela UFMG. Professor da Escola de Ciência da Informação da UFMG.
\end{abstract}

\section{E-mail: carlosaraujoufmg@gmail.com}

\section{ACESSO ABERTO}

Copyright: Esta obra está licenciada com uma Licença Creative Commons Atribuição 4.0 Internacional. $(\mathrm{cc}) \mathrm{EY}$

Conflito de interesses: Não se aplica.

Financiamento: Não se aplica.

Declaração de Disponibilidade dos dados: Todos os dados relevantes estão disponíveis neste artigo.

Recebido em: 26/04/2019.

Revisado em: 02/05/2019.

Aceito em: 09/05/2019.

\section{Como citar este artigo:}

ARAÚJO, Carlos A. Á. Dos estudos de usuários da informação aos estudos em práticas informacionais e cultura: uma trajetória de pesquisa. Informação em Pauta, Fortaleza, v. 4, n. especial, p. 121-136, maio 2019. DOI: https://doi.org/10.32810/25253468.ip.v4iEspecial.2019.41209.121-135

\section{RESUMO}

O objetivo deste artigo é apresentar a trajetória intelectual da professora Adriana Bogliolo Sirihal Duarte, tendo como eixo sua atuação na área de estudos de usuários da informação até a consolidação do grupo de pesquisa EPIC, Estudos em Práticas Informacionais e Cultura, do Programa de Pós-Graduação em Ciência da Informação da Universidade Federal de Minas Gerais (PPGCI/UFMG). Essa trajetória é apresentada em três momentos: a configuração da disciplina usuários da informação na UFMG; a ampliação das problemáticas e questões, entre os anos de 2008 e 2014; e o trabalho junto ao grupo de pesquisa EPIC. No artigo são ressaltadas as parcerias e atuações conjuntas da professora, bem como os avanços teóricos, metodológicos e empíricos dos diferentes membros do EPIC.

Palavras-chave: Adriana Bogliolo Sirihal Duarte. Estudos em Práticas Informacionais e Cultura. Estudos de usuários da informação.

\section{ABSTRACT}

The objective of this article is to present the intellectual trajectory of Adriana Bogliolo Sirihal Duarte, having as its axis her work in the area of information users studies until the consolidation of the research group EPIC, Information Practices and Culture Studies, linked to the PostGraduation Programm in Information Science of the Federal University of Minas Gerais (PPGCI/UFMG). This trajectory is presented in three moments: the configuration of the discipline information users in the UFMG; the expansion of issues between 2008 and 2014; and her work with the EPIC research group. In the article the partnerships of Adriana Bogliolo are highlighted, as well as the theoretical, methodological and empirical advances of the different researchers of the EPIC group.

Keywords: Adriana Bogliolo Sirihal Duarte. Information practices and culture studies. Information users studies. 


\section{INTRODUÇÃO}

A história da ciência é fascinante. Ela representa o desejo humano de conhecer coisas distintas (o mundo, a natureza, o universo, os animais, e também a nós mesmos), de maneiras distintas (utilizando métodos de observação, dedução, indução, experimentos) e, ainda, se relacionando com aspectos diversos como valores morais, elementos culturais, forças políticas, tabus religiosos. Ao longo de muitos séculos, mas sobretudo nos três últimos, o conhecimento humano cresceu imensamente em quantidade e qualidade, alterando profundamente nossa condição no mundo.

Mas a história da ciência, uma história de teorias, modelos, instrumentos, hipóteses, é sobretudo uma história de seres humanos. São pessoas que produziram e fizeram avançar a ciência. Pessoas que viveram em determinadas épocas, sujeitas a determinados modos de compreensão, categorias de pensamento, estruturas de premiação, valorização e marginalização. Assim, por exemplo, Galileu Galilei foi acusado e enfrentou um julgamento pela inquisição por suas teorias heliocêntricas. Charles Darwin escondeu por anos a sua teoria da evolução por medo das possíveis punições religiosas e sociais. Karl Marx chegou a ser expulso da França por conta de suas ideias. Sigmund Freud foi profundamente hostilizado pelos seus contemporâneos. Poderíamos prosseguir indefinidamente com essa lista. Tão fascinante quanto a história da ciência é a história dos seus protagonistas, dos cientistas - dos desafios que enfrentaram, das forças contra as quais tiveram que lutar, dos seus questionamentos e autocríticas que resultaram em mudanças em suas próprias teorias. Compreender a ciência é compreender não apenas seus produtos (o conhecimento científico propriamente dito) como, também, seus produtores (a vida dos pesquisadores).

Essa pequena introdução tem por objetivo demarcar o sentido deste texto. Este artigo foi produzido imediatamente após o falecimento da professora Adriana Bogliolo Sirihal Duarte, da Escola de Ciência da Informação da Universidade Federal de Minas Gerais (ECI/UFMG), ocorrido no dia 03 de dezembro de 2018. A intenção é apresentar alguns aspectos de sua vida intelectual, de seu percurso como pesquisadora. Ao mesmo tempo, este artigo se insere no âmbito da II Jornada em Práticas Informacionais, um evento do grupo de pesquisa EPIC, Estudos em Práticas Informacionais e Cultura, registrado no CNPq (Conselho Nacional de Desenvolvimento Científico e Tecnológico) e ligado ao Programa de Pós-Graduação em Ciência da Informação da Universidade Federal 
de Minas Gerais (PPGCI/UFMG), do qual a professora Adriana era líder, junto comigo. A existência desse grupo e a consolidação de sua temática de pesquisa - práticas informacionais - representam de maneira muito significativa a trajetória de pesquisa dela ao longo de 13 anos. Não foi o único campo de pesquisa ao qual ela se dedicou, mas foi, com certeza, o principal. Por esse motivo houve a opção de, neste artigo, apresentar a trajetória da professora Adriana a partir da evolução das preocupações com o estudo das práticas informacionais.

Neste sentido, cabe aqui uma pequena observação. Considerando que o desenvolvimento da disciplina Usuários da Informação, na ECI/UFMG, e do grupo EPIC, no âmbito do PPGCI/UFMG, foi um trabalho conjunto entre Adriana e eu, será absolutamente impossível tratar, neste texto, apenas dela. Nossas carreiras e trajetórias se entrelaçaram em vários momentos. Fomos verdadeiramente parceiros de ensino e pesquisa, além de amigos. Por esse motivo, este artigo também terá um certo tom pessoal, subjetivo. Tudo isso faz parte do processo da produção científica, inclusive as questões pessoais e sentimentais - o que torna ainda mais fascinante a descrição e o estudo da atividade científica. É a partir deste enquadramento que se propõe, a seguir, um mergulho em como se desenvolveu, na ECI e no PPGCI/UFMG, o pensamento que levou dos estudos de usuários da informação à perspectiva das práticas informacionais e suas interrelações com a cultura.

\section{O COMEÇO DE TUDO: ESTUDOS DE USUÁRIOS DA INFORMAÇÃO}

É sempre difícil demarcar quando é o "início" de uma história. Trata-se de uma decisão arbitrária, uma escolha. Em nosso caso, contudo, há um marco que claramente pode significar um ponto de partida. Em 2005, a ECI/UFMG abriu um concurso para uma vaga de professor adjunto da área de Usuários da Informação. Havia vários candidatos, entre eles, Adriana e eu. Após a realização das provas, fomos ambos aprovados. A ECI/UFMG ganhou mais uma vaga e foi decidido que seríamos os dois contratados. Em 2006, éramos, nós dois, professores desta área na escola, para ministrar a disciplina junto ao curso de biblioteconomia (para as turmas do matutino, do vespertino e do noturno) e o recém-criado sistemas de informação no Instituto de Ciências Exatas. 
0 primeiro desafio que se colocava então era o de decidir como deveria ser o programa dessa disciplina - quais conteúdos, quais textos, quais unidades programáticas, quais atividades e métodos didáticos. Não nos conhecíamos até acontecer o concurso mas, uma vez contratados como professores, imediatamente começamos uma relação amistosa e decidimos que iríamos ministrar a mesma disciplina, isto é, que iríamos montar um programa comum a ser usado por ambos.

Consultamos os programas da disciplina que haviam sido ministrados até então, na escola, e também programas ministrados em outras universidades. Numa avaliação geral, nos pareceu que a disciplina tinha um perfil bastante instrumental, como uma espécie de apoio para a gestão de bibliotecas e unidades/sistemas de informação. A maior parte dos conteúdos de praticamente todos os programas era relacionado a métodos quantitativos de coleta e tratamento de dados sobre perfil de usuários e diagnóstico/avaliação de bibliotecas e sistemas de informação, mapeando usos, frequências, indicadores de satisfação, itens de necessidade. Nossa primeira avaliação era de que a área tinha potencial para ser muito mais do que isso, sem prejuízo destes conteúdos. Percebemos a ausência de uma fundamentação teórica e conceitual para esses estudos. De uma forma geral, havia apenas uma definição instrumental de conceitos como requisito, demanda, necessidade e uso; uma apresentação também instrumental de métodos de coleta de dados e algumas noções de estatística para o tratamento descritivo dos dados; e a articulação com algumas noções de planejamento de bibliotecas, para o aproveitamento dos dados levantados.

Colocamo-nos o desafio de construir um outro tipo de programa para a disciplina. Para tanto, iniciamos uma busca na literatura da área. De maneira imediata, o que mais chamou nossa atenção foi a existência de uma relevante e extensa produção científica naquilo que era chamado "abordagem cognitiva" ou "abordagem alternativa" de estudos de usuários, principalmente os trabalhos em teoria sense-making de Brenda Dervin, o modelo information seeking process de Carol Kuhlthau, os modelos de comportamento informacional de Tom Wilson e o modelo integrativo de Chun Wei Choo. Já conhecíamos algumas dessas teorias e autores, mas nos espantou o fato de que suas contribuições até então - estávamos em 2006 - eram pouco ou nada incorporadas nos programas de disciplinas de Usuários da Informação no Brasil. A primeira decisão que tomamos foi a de incorporar essa abordagem com praticamente o mesmo grau de importância da abordagem quantitativa instrumental até então em vigor. A disciplina teria, então, dois 
momentos distintos: introdução, apresentação e exemplificação da primeira abordagem, a "tradicional"; e o mesmo conteúdo para a abordagem "alternativa".

Ainda nos parecia pouco. Sentíamos falta de uma fundamentação conceitual para cada uma das abordagens, que demonstrasse de onde vinham os conceitos, os métodos de estudo, os objetivos de cada uma. Foi a partir dessa preocupação que nos dedicamos a um questionamento e um aprofundamento teórico em cada uma das abordagens. No caso da abordagem dita tradicional, o movimento foi o de buscar compreender o positivismo e o funcionalismo, as duas matrizes teóricas dessa abordagem. Mergulhamos nos fundamentos das ciências humanas e sociais para apontar os elementos centrais dessas matrizes, bem como as suas apropriações por parte dos estudos de usuários da informação. 0 positivismo, como se sabe, representa a transposição, para as ciências humanas e sociais, do mesmo modo de raciocínio das ciências naturais (exatas e biológicas). Isso significa a concepção de que a realidade possui um fundamento nela mesma, isto é, que pode ser objetivamente compreendida pelo método científico; a pressuposição de que a realidade é composta por regularidades, que podem ser expressas em leis; e que os aspectos da realidade relevantes são aqueles que podem ser observados e quantificados. Já o funcionalismo, que é uma vertente ou aplicação dos princípios positivistas, baseia-se numa concepção organísmica da realidade humana, isto é, compreendo as ações, instituições e atores humanos como parte de uma estrutura maior exercendo determinadas funções ou tarefas para a manutenção do equilíbrio dessa estrutura (ou, eventualmente, desempenhando determinadas disfunções).

No caso da abordagem dita alternativa, buscamos nos trabalhos dos autores mais destacados os seus fundamentos, e encontramos elementos relacionados ao construtivismo, ao interacionismo simbólico, à fenomenologia e à etnometodologia. São todas abordagens das ciências humanas e sociais que se construíram em oposição ao positivismo, calcadas nas ideias de que a causalidade dos fenômenos humanos e sociais é distinta dos fenômenos naturais (o ser humano é um sujeito consciente das suas ações, possui intencionalidade, atribui significado ao que faz) e que o caráter situacional e contextual dos fenômenos é decisivo (os fenômenos são profundamente imbricados nas realidades econômicas, culturais, politicas nos quais se inserem). Decidimos, portanto, que a disciplina deveria incluir e contemplar aspectos relacionados tanto ao positivismo e ao funcionalismo quanto às perspectivas compreensivas e fenomenológicas, buscando 
ver as contribuições delas para o desenho do campo de estudos de usuários da informação.

Outra questão que nos parecia fundamental é que a disciplina não deveria ser apenas teórica, mas envolver também um trabalho de efetiva pesquisa por parte dos alunos. Nos programas que havíamos analisado, havia sempre a previsão de um trabalho de campo a ser realizado pelos alunos. Como nosso programa estava dividido em duas partes, concluímos que deveria haver dois trabalhos de campo, ou um trabalho de campo em dois momentos: um com uma pesquisa seguindo os moldes da abordagem tradicional, outro a partir dos parâmetros da abordagem cognitiva. Isso implicava a compreensão de duas maneiras de aproximação da realidade: uma basicamente quantitativa, buscando dados sociodemográficos dos usuários, indicadores de uso, de frequência, de satisfação; e outro buscando significados, interpretações, impressões, por parte dos sujeitos.

Uma vez concluída essa primeira tarefa, resolvemos ministrar em conjunto a disciplina no segundo semestre de 2006: ela assistindo às minhas aulas, eu assistindo às aulas delas. Fazíamos a seguir uma sessão de críticas e comentários, íamos incorporando um do outro sugestões, exemplos, métodos, e fomos com isso consolidando a maneira como a disciplina seria ministrada daí em diante e também sua importância dentro dos cursos de biblioteconomia e sistemas de informação, e dentro da área de ciência da informação. Nos preocupamos também em mostrar para a comunidade científica o nosso trabalho. Resolvemos apresentar um pouco de nossas inquietações com a área em congressos científicos (ARAÚJO, 2007; ARAÚJO, 2008; ARAÚJO; JILOCHKIN; SIRIHAL DUARTE, 2008; SIRIHAL DUARTE, 2011) e, depois, resolvemos apresentar a maneira como se deu esse processo de construção da disciplina (ARAÚJO, 2009; ARAÚJO, 2010b; SIRIHAL DUARTE, 2012; ARAÚJO; SIRIHAL DUARTE, 2014; ARAÚJO, 2014b).

\section{A AMPLIAÇÃO DAS QUESTÕES: DE 2008 A 2014}

Nos anos seguintes, novos desafios foram se apresentando. As primeiras apresentações em congressos e publicações em periódicos provocaram interlocuções interessantes com outros pesquisadores brasileiros. Percebemos que havia uma grande produção científica relevante sobre o assunto, embora não sob a designação de "usuários da informação" - estudos em mediação da informação, competência informacional, 
informação e cultura, informação e sociedade, entre outros. Particularmente no âmbito do grupo de trabalho 3 (GT 3 - Mediação, circulação e apropriação da informação) da ANCIB, a Associação Nacional de Pesquisa em Ciência da Informação, pesquisadores vinham apresentando resultados de pesquisas com temas e contribuições fundamentais para se entender os usuários da informação, ainda que não usassem essa expressão. Era preciso conhecer essa produção, estabelecer diálogos com ela e incorporar suas contribuições, como foi feito, por exemplo, em SIRIHAL DUARTE (2009) e ARAÚJO (2012).

Um outro desafio se deu quando a ECI/UFMG criou, em 2008, o curso de graduação em arquivologia e, em 2009, o curso de graduação em museologia. Usuários da informação era uma disciplina presente nos dois cursos, e era preciso adaptar o programa da disciplina para incorporar questões, aspectos e demandas destas áreas de conhecimento. Começamos, então, a ler, discutir e estudar questões relativas a estudos de usuários de arquivos e estudos de público de museus, de forma a ampliar o escopo conceitual e teórico da disciplina de Usuários da Informação (ARAÚJO, 2013; 2014a)

Além disso, começamos algumas interlocuções internacionais, o que nos conduziu a uma série de questionamentos e descobrimentos. A primeira dessas interlocuções se deu com Martha Sabelli, pesquisadora da Universidad de la Republica, Uruguai. Mas foi 2014 o ano decisivo. Neste ano, resolvemos enviar um trabalho para o ISIC: The information behaviour conference, o evento mais importante do mundo na área de usuários da informação, que iria acontecer em Leeds, Inglaterra. Escrevemos junto o artigo e o enviamos. 0 trabalho foi aprovado (ARAÚJO; SIRIHAL DUARTE, 2014) e viajamos para a Inglaterra para participar do evento. Foi uma experiência decisiva. Conhecemos pesquisadores da Europa, da América, da Ásia e da África. Assistimos a apresentações muito distintas, com referenciais teóricos e objetos empíricos muito diferentes. Nos identificamos com alguns, claramente não nos agradaram outros. Mas a experiência foi importante para nos situarmos em relação à produção científica mundial. Naturalmente, já conhecíamos muito dessa produção pelas leituras, mas estar em interação face a face com os pesquisadores, e acompanhar tanto as apresentações quanto os debates, foi fundamental. Na volta da Inglaterra, ainda passamos pela Espanha, para alguns dias de reunião com Aurora González Teruel, pesquisadora da área vinculada à Universitat de Valencia. Assim como o contato com Martha Sabelli, este outro momento de diálogo foi decisivo para pensarmos sobre nossa proposta própria para a área, sua inserção no campo como um todo e sua especificidade. 
Por fim, cabe destacar a ampliação do quadro conceitual que experimentamos ao longo destes anos, com a incorporação de uma terceira maneira de se estudar os usuários, situada num quadro teórico distinto das abordagens "tradicional" e "alternativa". 0 modelo cognitivo, com sua lógica mecânica baseada na ideia de estímulo/resposta, sua apreensão dos sujeitos unicamente a partir de suas cognições e isolados de sua vivência social, não pareciam responder adequadamente às demandas de nossas pesquisas, nem mesmo combinar com nossos referenciais calcados no construcionismo e na fenomenologia.

Essa ampliação se deu com o tensionamento da categoria "usuário da informação" por meio de duas categorias, "sujeito" e "informação". Na perspectiva dos sujeitos, aprofundamos as leituras e estudos nas ciências sociais e humanas em torno do entendimento das três grandes correntes de estudo que as compõem: a positivista/funcionalista, a crítica/marxista e a compreensiva/fenomenológica. Do ponto de vista da informação, avançamos nos fundamentos da ciência da informação, a partir do estudo das três grandes perspectivas de estudo que compõem a área: a fisicista, a cognitivista e a pragmaticista ou sociocultural. Esse foi, aliás, o trabalho que apresentamos em Leeds e sobre o qual buscamos o escrutínio da comunidade internacional. Tratava-se de perceber que o estudo do sujeito informacional perpassava dois quadros de referência distintos (três modelos de estudo dos sujeitos; três modelos de estudo da informação) resultando num quadro complexo de possibilidades de estudo e pesquisa.

Durante esse processo, foi ficando portanto cada vez mais clara nossa insatisfação com o modelo cognitivo ou "alternativo" de estudos de usuários, em termos de seu poder explicativo. Vínhamos, intuitivamente, apontando alguns caminhos alternativos de estudo, que fomos desenvolvendo ao longo dos anos - uma perspectiva fenomenológica (GANDRA; SIRIHAL DUARTE, 2012), interacionista (ARAÚJO, 2010a), vinculada ao paradigma social da ciência da informação (ARAÚJO, 2010b; ROCHA; SIRIHAL DUARTE, 2013; MOREIRA; SIRIHAL DUARTE, 2016), ao pensamento crítico (PINTO; ARAÚJO, 2012), à cognição distribuída (ROCHA; PAULA; SIRIHAL DUARTE, 2016) e à abordagem clínica da informação (ANTUNES; PAULA; SIRIHAL DUARTE, 2016).

E foi nesse momento, nos debates internacionais, nas leituras sobre o assunto, nos congressos, nas pesquisas, que descobrimos a abordagem das "práticas informacionais". Conhecemos alguns autores, alguns textos, e percebemos que estava aí a possibilidade de 
avançarmos em nossas preocupações e fazer confluir nossas possibilidades de constituição de um campo de pesquisa que atendia nossos interesses.

\section{A CONSOLIDAÇÃO DE UMA PROPOSTA: A CRIAÇÃO DO EPIC}

Como resultado de todos esses processos, resolvemos, Adriana e eu, criar um grupo de pesquisa no final de 2014. Na verdade, desde 2007 já tínhamos grupos de estudos com nossos orientandos de mestrado e doutorado do PPGCI/UFMG. Esses grupos funcionavam de maneira informal, às vezes com uma agenda de encontros mais intensa, algumas vezes menos, dependendo da quantidade de mestrandos ou doutorandos envolvidos com a temática. Nesse período, orientamos dissertações e teses com realidades empíricas muito variadas, tais como profissionais do sexo (SILVA, 2008), ouvintes assíduos de rádio (PESSOA, 2010), professores da rede municipal (PINTO, 2012), bibliotecários no trabalho de indexação (ALONSO, 2012), bibliotecários realizando estudos de usuários (SEPÚLVEDA, 2012), pessoas da terceira idade (GANDRA, 2012), deficientes visuais (ROCHA, J., 2013), bibliotecários na atividade de indexação (ARAÚJO, E., 2013), diferentes profissionais da informação (ROCHA, E., 2013) e usuários de um sistema de informação de extensão universitária (TERTO, 2013). Tais pesquisas buscavam avançar numa perspectiva além das abordagens tradicional e cognitiva, mas não havia ainda uma proposta única, um referencial comum, senão fragmentos de aproximações.

A ideia de trabalhar com práticas informacionais nos situava no âmbito de um movimento internacional que se construiu no campo de estudos de usuários da informação - representado por, entre outros, pesquisadores da Finlândia como Reijo Savolainen, Sanna Talja e Kimmo Tuominem; da Suécia, como Annemarie Lloyd; e do Canadá, como Pam McKenzie). Ao mesmo tempo, nossas pesquisas empíricas e reflexões epistemológicas nos apontavam para uma certa originalidade no campo, mobilizando determinadas categorias e formas de compreensão específicas - que nos aproximavam, principalmente, do conceito de cultura e de uma abordagem mais antropológica. Em função disso, e como forma de amarrar todas essas questões (nossos diálogos no GT 3 da Ancib, com os parceiros internacionais, com nossas próprias percepções conceituais e as pesquisas que orientávamos) surgiu a ideia de criar o grupo, associando as duas ideias, Inf. Pauta, Fortaleza, CE, v. 4, n. especial, maio 2019 | ISSN 2525-3468 
práticas informacionais e cultura. Logo no início, juntou-se ao grupo o professor Cláudio Paixão Anastácio de Paula, que já vinha realizando diversas parcerias conosco, e a professora Eliane Cristina de Freitas Rocha, recém-empossada como professora na ECI e que havia feito o doutorado sob orientação da Adriana. A ideia de "grupo" nos animava imensamente: a possibilidade de trabalhar em conjunto, compartilhar ideias e leituras, construir conjuntamente nossa perspectiva, aproveitando as singularidades e competências de cada um. Também nesse momento foi definida a marca do grupo, apresentada abaixo:

Figura 1 - Logomarca do EPIC.

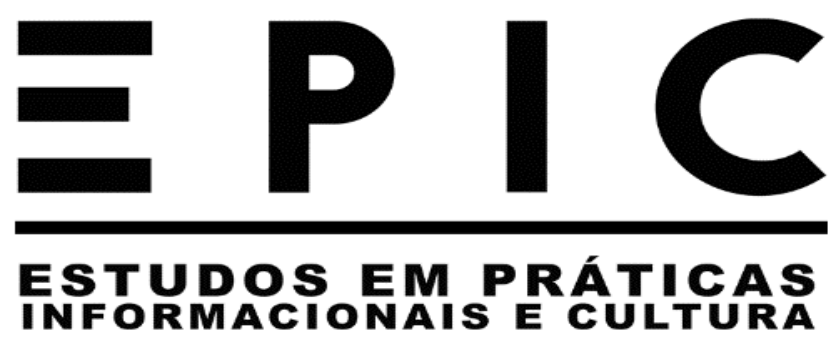

A partir de 2015 o grupo passou efetivamente a existir, e nos unimos em torno da consolidação e clarificação de uma perspectiva que deveria ser nossa, original, e que poderia ser uma referência para as novas pesquisas a serem realizadas dali em diante. Isso de fato aconteceu, e desde então um conjunto de novas pesquisas foi realizado, também com realidades empíricas muito diversas tais como nativos digitais (ANTUNES, 2015), docentes e discentes em relação de orientação (SÁ, 2015), formação dos arquivistas (VAZ, 2015), mães de crianças alérgicas (BARROS, 2016), clientes de serviços de estética (VASCONCELOS, 2016), visitantes de museu (GANDRA, 2017), detentas grávidas (BARBOSA, 2017), usuários de redes sociais interagindo a partir de acontecimentos políticos (BERTI, 2018), nativos digitais na biblioteca escolar (PAIVA, 2018), pesquisadores de um instituto de pesquisa (ROCHA, 2018), blogueiros literários (SÁ, 2018) e bibliotecários de serviços de referência (LIMA, 2018). 
A existência do grupo de pesquisa também foi importante no sentido da nossa internacionalização. Passaram a fazer parte formalmente do grupo as professoras Martha Sabelli (Uruguai) e Aurora González Teruel (Espanha), e um primeiro trabalho em conjunto foi apresentado no XI Encontro de Diretores e X Encontro de Docentes de Escolas de Biblioteconomia e Ciência da Informação do Mercosul (SIRIHAL DUARTE; SABELLI; GONZÁLEZ TERUEL; ROCHA; ARAÚJO, 2016). Pouco depois ingressaram no grupo Silvia Albornoz, da Universidad Nacional de La Plata, Argentina, e Edilma Naranjo, da Universidad de Antioquia, Colômbia.

Enquanto grupo, e engajados num processo efetivo de colaboração e construção coletiva, sintonizamos nossa proposta de pesquisa com as perspectivas contemporâneas da ciência da informação e com as discussões teóricas em práticas informacionais, a partir do conceito de intersubjetividade, buscando um equilíbrio entre as dimensões coletivas e individuais dos fenômenos informacionais, contemplando também as questões emocionais e afetivas envolvidas nos processos, as dinâmicas de significação e produção de sentidos, a importância do enraizamento das práticas nos contextos nos quais tomam existência e o caráter ativo dos sujeitos. Nos apropriamos de diferentes conceitos, como conhecimento, imaginação, sociabilidade, identidade e práxis, e as reconstruímos como rede conceitual em torno das ideias de práticas informacionais e cultura.

O EPIC atingiu seu ponto mais alto de consolidação em 2018, quando realizou em março a I Jornada em Práticas Informacionais. Foram convidados palestrantes de distintas áreas para tratar de temas como praxiologia, construcionismo social, interacionismo simbólico, representações sociais e etnografia. Também foram ministradas palestras das pesquisadoras estrangeiras do grupo sobre seus temas de pesquisa. Os debates foram ricos e sinalizaram a maturidade das nossas questões. Em 2018 também o grupo acolheu dois pesquisadores em realização de estágio de pós-doutorado.

Nos últimos anos, algumas publicações de membros do grupo demonstraram essa maturidade da nossa proposta de pesquisa (ARAÚJO, 2016; ROCHA; GANDRA; ROCHA, 2017; ARAÚJO, 2017; BERTI; ARAÚJO, 2017; SIRIHAL DUARTE; ARAÚJO; PAULA, 2017; ROCHA, SIRIHAL DUARTE; PAULA, 2017; ROCHA; GANDRA, 2018; ARAÚJO; SIRIHAL DUARTE; DUMONT, 2019). Hoje, o EPIC é um grupo consolidado, com a participação de dez pesquisadores doutores, membros de outros quatro países, parcerias com professores de várias universidades brasileiras, e ao qual se vinculam diversos alunos de 
iniciação científica, mestrado e doutorado, além de profissionais bibliotecários, arquivistas e museólogos atuantes em diferentes instituições.

\section{CONSIDERAÇÕES FINAIS}

A proposta deste artigo foi discutir o percurso intelectual e profissional de Adriana Bogliolo, a partir de sua atuação no campo dos estudos de usuários da informação, até a chegada à perspectiva das práticas informacionais. Contudo, a vida de um pesquisador nunca é centrada em apenas uma temática, um aspecto. Adriana, ao longo de sua carreira, ministrou aulas, pesquisou e publicou sobre diversos outros temas, nos quais tem contribuições significativas: inclusão digital, leitura e formação do leitor, biblioteca escolar, livro eletrônico, extensão universitária. Cada um deles renderia um outro artigo. Não caberia desenvolver nada sobre tais tópicos, nos limites deste texto.

Ao mesmo tempo, ao falar da trajetória dela rumo às práticas informacionais, é impossível falar apenas dela. É preciso mencionar seus parceiros, seus orientandos, seus alunos, seus interlocutores. Ninguém faz ciência só, assim como não vivemos sós. Vivemos imersos em redes de relações, de influências, de aprendizados, de parcerias. E, na verdade, essa é talvez a principal contribuição da professora Adriana. Para além de toda a sua produção com textos, apresentações, aulas e debates, Adriana foi uma amiga e companheira, parceira, atenciosa, generosa e muito comprometida. E é com essa imagem, parte significativa do que ela foi, que gostaria de terminar esse texto.

\section{REFERÊNCIAS}

\section{ALONSO, L. F. C. A. Manifestações externas} na indexação: uma construção social da realidade. 2012. Dissertação (Mestrado em Ciência da Informação) - Universidade Federal de Minas Gerais, Belo Horizonte, 2012.

ANTUNES, M. L. A. Comportamento informacional em tempos de Google. 2015. Dissertação (Mestrado em Ciência da Informação) - Universidade Federal de Minas Gerais, Belo Horizonte, 2015.
ANTUNES, M. L. A. ; PAULA, C. P. A.; SIRIHAL DUARTE, A. B.. Abordagem clínica da informação: um projeto em construção. In: EBCIM - ENCONTRO DE DIRETORES, 11; ENCONTRO DE DOCENTES DE ESCOLAS DE BIBLIOTECONOMIA E CIÊNCIA DA INFORMAÇÃO DO MERCOSUL, 10. 2016, Belo Horizonte. Anais... Belo Horizonte: Escola de Ciência da Informação da UFMG, 2016.

ARAÚJO, C. A. Á. A Perspectiva de estudos sobre os sujeitos na Arquivologia, na 
Biblioteconomia e na Museologia. Em Questão, v. 19, 2013, p. 213-238.

ARAÚJO, C. A. Á. Abordagem interacionista de estudos de usuários da informação. Ponto de Acesso, v. 4, 2010a, p. 2-32.

ARAÚJO, C. A. Á. Estudos de usuários conforme o paradigma social da Ciência da Informação: desafios teóricos e práticos de pesquisa. Informação \& informação, v. 15, n.2, 2010b, p. 23-39.

ARAÚJO, C. A. Á. Estudos de usuários da informação: comparação entre estudos de uso, de comportamento e de práticas a partir de uma pesquisa empírica. Informação em Pauta, v. 1, 2016, p. 61-78.

ARAÚJO, C. A. Á. Estudos de usuários: pluralidade teórica, diversidade de objetos. In: ENCONTRO NACIONAL DE PESQUISA EM CIÊNCIA DA INFORMAÇÃO, 9., 2008, São Paulo. Anais... São Paulo: Associação Nacional de Pesquisa e Pós-Graduação em Ciência da Informação, 2008.

ARAÚJO, C. A. Á. Estudos de usuários: uma abordagem na linha ICS. In: CABRAL, A. M. R.; REIS, A. S. (Org.). Informação, cultura e sociedade: interlocuções e perspectivas. Belo Horizonte: Novatus, 2007, p. 81-100.

ARAÚJO, C. A. Á. O que são 'práticas informacionais'?. Informação em Pauta, v. 2, 2017a, p. 217-236.

ARAÚJO, C. A. Á. Paradigma social nos estudos de usuários da informação: abordagem interacionista. Informação \& Sociedade, v. 22, n.1, 2012, p. 145-159.

ARAÚJO, C. A. Á. Perspectivas contemporâneas de estudos de usuários da informação: diálogos com estudos de usuários de arquivos, bibliotecas e museus. In: CASARIN, H. C. S. (Org.). Estudos de usuário da informação. Brasília: Thesaurus, 2014a, p. 19-46.

ARAÚJO, C. A. Á. Um mapa dos estudos de usuários da informação no Brasil. Em Questão, v. 15, 2009, p. 11-26.

ARAÚJO, C. A. Á. Usuários da informação: construção de conceitos e perspectivas de estudo. In: RENDÓN ROJAS, M. Á. (Org.). El ser, conocer e hacer en bibliotecología / ciencia de la información / documentación. México: UNAM/IIBI, 2014b, p. 29-58.

ARAÚJO, C. A. A.; JILOCHKIN, A. M. N.; SIRIHAL DUARTE, A. B. Mapeamento temático dos estudos de usuários da informação: uma análise dos artigos publicados no periódico Ciência da Informação. In: CINFORM - Encontro Nacional de Ensino e Pesquisa da Informação, 8. 2008, Salvador. Anais... Salvador: Universidade Federal da Bahia, 2008.

ARAÚJO, C. A. A. ; SIRIHAL DUARTE, A. B. The informational subject at the intersection of information science and the human and social sciences. In: ISIC - Information Behaviour Conference, 10. 2014, Leeds. Proceedings... Leeds: University of Leeds, 2014.

ARAÚJO, C. A. Á.; SIRIHAL DUARTE, A. B. ; DUMONT, L. M. M. As perspectivas de estudos sobre os sujeitos no PPGCI/UFMG. Perspectivas em Ciência da Informação, v. 24,2019, p. 85-101.

ARAUJO, E. P. O. Tomada de decisão organizacional e subjetividade: análise das dimensões simbólico-afetivas no uso da informação em processos decisórios. 2013. Dissertação (Mestrado em Ciência da Informação) - Universidade Federal de Minas Gerais, Belo Horizonte, 2013.

BARBOSA, A. G. Práticas informacionais das apenadas do Centro de Referência a Gestante Privada de Liberdade de Vespasiano-MG. 2017. Dissertação (Mestrado em Ciência da Informação) Universidade Federal de Minas Gerais, Belo Horizonte, 2017.

BARROS, F. M. M. Protagonismo nas práticas informacionais de mães de crianças alérgicas. 2016. Dissertação (Mestrado em Ciência da Informação) Universidade Federal de Minas Gerais, Belo Horizonte, 2016.

BERTI, I. C. L. W. Práticas e regime de informação - os acontecimentos "carta de Temer a Dilma" e "Marcela Temer: bela, recatada e do lar". 2018. Tese (Doutorado em Ciência da Informação) - Universidade Federal de Minas Gerais, Belo Horizonte, 2018. 
BERTI, I. C. L. W.; ARAÚJO, C. A. Á. Estudos de usuários e práticas informacionais: do que estamos falando?. Informação \& Informação, v. 22, 2017, p. 389-401.

\section{GANDRA, T. K. Inclusão digital na terceira} idade: um estudo de usuários sob a perspectiva fenomenológica. 2012. Dissertação. (Mestrado em Ciência da Informação) - Universidade Federal de Minas Gerais, Belo Horizonte, 2012.

GANDRA, T. K. Práticas informacionais dos visitantes do Museu Itinerante Ponto UFMG. 2017. Tese (Doutorado em Ciência da Informação) - Universidade Federal de Minas Gerais, Belo Horizonte, 2017.

GANDRA, T. K. ; SIRIHAL DUARTE, A. B. Usuários da informação sob a perspectiva fenomenológica: revisão de literatura e proposta de postura metodológica de pesquisa. Informação \& Sociedade, v. 22, 2012, p. 13-23.

LIMA, G. M. C. Serviços de referência: práticas informacionais do bibliotecário. 2018. Dissertação (Mestrado em Ciência da Informação) - Universidade Federal de Minas Gerais, Belo Horizonte, 2018.

MOREIRA, F. M.; SIRIHAL DUARTE, A. B. O paradigma social da informação e as teorias sociais: relações e contribuições. Pesquisa Brasileira em Ciência da Informação e Biblioteconomia, v. 11, 2016, p. 169-178.

PAIVA, R. M. V. A biblioteca escolar e os nativos digitais. 2018. Tese (Doutorado em Ciência da Informação) - Universidade Federal de Minas Gerais, Belo Horizonte, 2018.

PESSOA, M. T. A relação entre ouvintes assíduos e o rádio: um estudo de usuários da informação a partir de uma perspectiva compreensiva. 2010. Dissertação (Mestrado em Ciência da Informação) - Universidade Federal de Minas Gerais, Belo Horizonte, 2010.

PINTO, F. V. M. Práticas informacionais na organização político-sindical dos professores da rede municipal de Belo Horizonte. 2012. Dissertação (Mestrado em Ciência da Informação) - Universidade Federal de Minas Gerais, Belo Horizonte, 2012.
PINTO, F. V. M.; ARAÚJO, C. A. Á. Contribuição ao campo de usuários da informação: em busca dos paradoxos das práticas informacionais. Transinformação, v. 4, n. 3, set./dez. 2012., p. 219-226.

ROCHA, E. C. F. Usuário da informação, um velho (?) (des)conhecido: Usuários da informação em diferentes profissões da informação. 2013. Tese (Doutorado em Ciência da Informação) - Universidade Federal de Minas Gerais, Belo Horizonte, 2013.

ROCHA, E. C. F.; GANDRA, T. K.; ROCHA, J. A. $P$. Práticas informacionais: nova abordagem para os estudos de usuários da informação.

Biblios, v. 68, 2017, p. 96-109.

ROCHA, E. C. F.; SIRIHAL DUARTE, A. B. Reflexões sobre os paradigmas de estudo da usabilidade na Ciência da Informação. Datagramazero, v. 14, 2013, p. 03.

ROCHA, J. A. P. (In) Acessibilidade na web para pessoas com deficiência visual: um estudo de usuários à luz da cognição situada. 2013. Dissertação (Mestrado em Ciência da Informação) - Universidade Federal de Minas Gerais, Belo Horizonte, 2013.

ROCHA, J. A. P. A produção do conhecimento como cognição distribuída: práticas informacionais no fazer científico. 2018. Tese (Doutorado em Ciência da Informação) - Universidade Federal de Minas Gerais, Belo Horizonte, 2018.

ROCHA, J. A. P..; PAULA, C. P. A.; SIRIHAL DUARTE, A. B. A cognição distribuída como referencial teórico para os estudos de usuários da informação. Informação \& Sociedade, v. 26, 2016, p. 91-105.

ROCHA, J. A. P.; GANDRA, T. K. Práticas informacionais: elementos constituintes. Informação \& Informação, v. 23, 2018, p. 566-595.

ROCHA, J. A. P.; SIRIHAL DUARTE, A. B.; PAULA, C. P. A. Modelos de práticas informacionais. Em Questão, v.23, n. 1, jan.abr./2017, p.36-61.

SÁ, J. P. S. Ler e compartilhar na web: práticas informacionais de blogueiros literários. 2018. Dissertação (Mestrado em Ciência da Informação) - Universidade 
Federal de Minas Gerais, Belo Horizonte, 2018.

\section{SÁ, R. M. C. Compartilhamento do} conhecimento e o processo de orientação de discentes de pós-graduação stricto sensu. 2015. Dissertação (Mestrado em Ciência da Informação) - Universidade Federal de Minas Gerais, Belo Horizonte, 2015.

SEPÚLVEDA, M. I. M. A relação dos bibliotecários com a profissão, com a rotina profissional e com os usuários a partir de uma perspectiva compreensiva. 2012. Dissertação (Mestrado em Ciência da Informação) - Universidade Federal de Minas Gerais, Belo Horizonte, 2012.

SILVA, R. As práticas informacionais das profissionais do sexo da zona boêmia de Belo Horizonte. 2008. Dissertação (Mestrado em Ciência da Informação) Universidade Federal de Minas Gerais, Belo Horizonte, 2008.

SIRIHAL DUARTE, A. B. Inclusão digital e competência informacional: estudo de usuários da informação digital. In: ENCONTRO NACIONAL DE PESQUISA EM CIÊNCIA DA INFORMAÇÃO, 10. 2009, João Pessoa. Anais... João Pessoa: Associação Nacional de Pesquisa e Pós-Graduação em Ciência da Informação, 2009.

SIRIHAL DUARTE, A. B. Mediação da informação e estudos de usuários: interrelações. InCID: Revista de Ciência da Informação e Documentação, v. 3, 2012, p. 7086.

SIRIHAL DUARTE, A. B. Mediação, usos e usuários: reflexões e análise de caso. In: ENCONTRO NACIONAL DE PESQUISA EM
CIÊNCIA DA INFORMAÇÃO, 12. 2011. Brasília. Anais... Brasília: Associação Nacional de Pesquisa e Pós-Graduação em Ciência da Informação, 2011.

SIRIHAL DUARTE, A. B.; SABELLI, M.; GONZÁLEZ TERUEL, A.; ROCHA, E. C. F.; ARAÚJO, C. A. Á. Práticas pedagógicas na área de usuários da informação em três universidades iberoamericanas. In: EBCIM ENCONTRO DE DIRETORES, 11; ENCONTRO DE DOCENTES DE ESCOLAS DE BIBLIOTECONOMIA E CIÊNCIA DA INFORMAÇÃO DO MERCOSUL, 10. 2016, Belo Horizonte. Anais... Belo Horizonte: Escola de Ciência da Informação da UFMG, 2016. v. XI. p. 596-609.

SIRIHAL DUARTE, A. B.; ARAÚJO, C. A. Á.; PAULA, C. P. A. Práticas informacionais: desafios teóricos e empíricos de pesquisa. Informação em Pauta, v. 2, 2017, p. 111-135.

TERTO, A. L. V. A extensão universitária e o Sistema de Informação da Extensão (SIEX/UFMG): um estudo de usuários a partir de uma perspectiva compreensiva. 2013. Dissertação (Mestrado em Ciência da Informação) - Universidade Federal de Minas Gerais, Belo Horizonte, 2013.

VASCONCELOS, P. M. As práticas informacionais das clientes dos serviços de estética. 2016. Dissertação (Mestrado em Ciência da Informação) - Universidade Federal de Minas Gerais, Belo Horizonte, 2016.

VAZ, G. A. A importância dos estudos de usuários na formação do arquivista. 2015. Dissertação (Mestrado em Ciência da Informação) - Universidade Federal de Minas Gerais, Belo Horizonte, 2015. 